\title{
Criptococosis vertebral. Comunicación de un caso y revisión bibliográfica
}

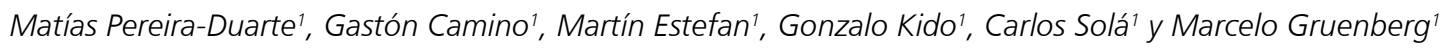

'Hospital Italiano de Buenos Aires, Buenos Aires, Argentina. Recibido: 12 de septiembre de 2018 Aceptado: 6 de marzo de 2019

Correspondencia a: Matias Pereira Duarte matias.pereira@hospitalitaliano. org.ar

\section{Vertebral cryptococosis. Case report and literature review}

Cryptococcosis is an infectious disease caused by a ubiquitous encapsulated yeast called Cryptococcus neoformans, it is usually associated with immunosuppressed patients. Osteomyelitis occurs in 5-10\%, the spine involvement is one of the most reported. The purpose of this work is to present a case of isolated vertebral cryptococcosis and detail the results of a literature review. The treatment protocol is not yet established but it is recommended to start with aggressive intravenous therapy and continue with a suppressive treatment orally during a variable time. Surgical indication is considered in lesions that affect the spinal stability, deformity or neurological compromise and for local infectious control.

Keywords: Spinal cryptococcosis; osteomyelitis/cryptococcal spondylitis; cryptococcosis in transplant patients; cryptococcosis in HIV negative patient.

Palabras clave: Criptococosis vertebral; osteomielitis/espondilitis criptocóccica; criptococosis en trasplantados; criptococosis en paciente VIH negativo.

\section{Introducción}

L a criptococosis es una micosis sistémica producida por un hongo levaduriforme encapsulado denominado Cryptococcus neoformans. Es una enfermedad universal que, si bien puede afectar a personas inmunocompetentes, 80 a $90 \%$ de las criptococosis ocurren en pacientes con inmunidad celular deficiente, frecuentemente pacientes con infección por VIH con recuentos de linfocitos CD4 menores 100 céls $/ \mathrm{mm}^{31,2}$. La infección primaria se adquiere por inhalación de basidiosporas en forma de aerosol liberadas a partir de las heces de las aves. Los órganos más frecuentemente involucrados son el sistema nervioso central (SNC) y los pulmones ${ }^{1}$. En personas inmunocompetentes la inmunidad celular y humoral es suficiente para controlar el hongo en los alvéolos pulmonares, y suele no advertirse debido a que transcurre en forma asintomática o con síntomas inespecíficos y autolimitados ${ }^{2}$. Los casos de criptococosis localizados fuera del SNC y de los pulmones son infrecuentes. La osteomielitis ocurre en 5-10\% de los pacientes con enfermedad criptocóccica diseminada ${ }^{2-4}$. Las infecciones criptocóccicas esqueléticas aisladas ocurren con menos frecuencia aun, siendo la afección de la columna vertebral una de las más reportadas ${ }^{1,25-7}$.

Se presenta un caso de criptococosis vertebral aislada en un paciente sometido a un trasplante renal, tratado quirúrgicamente y se realiza una revisión bibliográfica de la literatura especializada.

\section{Caso clínico}

Varón de 65 años de edad con antecedentes de una diabetes mellitus tipo II no insulino requiriente de 25 años de evolución, hipertensión arterial e insuficiencia renal crónica. Sometido a un trasplante renal hacía tres años en tratamiento inmunosupresor con tacrolimus $2 \mathrm{mg} /$ día, micofenolato $180 \mathrm{mg} /$ día y $\beta$-metilprednisona $4 \mathrm{mg} /$ día.

Consultó por una dorsalgia mecánica de tres meses de evolución que se incrementaba en bipedestación, sin irradiación ni déficit neurológico.

Se realizó un hemograma: leucocitos 8.400 céls $/ \mathrm{mm}^{3}$, $74 \%$ de polimorfonucleares, velocidad de eritosedimentación (VES) $41 \mathrm{~mm} / \mathrm{h}$ y una proteína $\mathrm{C}$ reactiva (PCR) $17,2 \mathrm{mg} / \mathrm{l}$ (valor de referencia $<5 \mathrm{mg} / \mathrm{l}$ ).

En una TC se encontró una lesión ósea lítica en los cuerpos vertebrales de la tercera y cuarta vértebra dorsal (T3 y T4) con compromiso del pedículo, lámina y articulación costo-transversa izquierda de T3 e invasión costal. Además se evidenció una masa paravertebral izquierda que protruía hacia el parénquima pulmonar (Figura 1 y 2). No había lesiones en otra localización.

Se indicó una punción biopsia guiada por TC cuyo estudio histopatológico informó la presencia de necrosis ósea y numerosas levaduras capsuladas con tinción PAS (Periodic Acid-Schiff) y Grocott positivas, compatible con una osteomielitis por Cryptococcus spp (Figura 3). Para confirmar el diagnóstico, se realizó una punción lumbar. El LCR fue positivo para la detección del antí- 

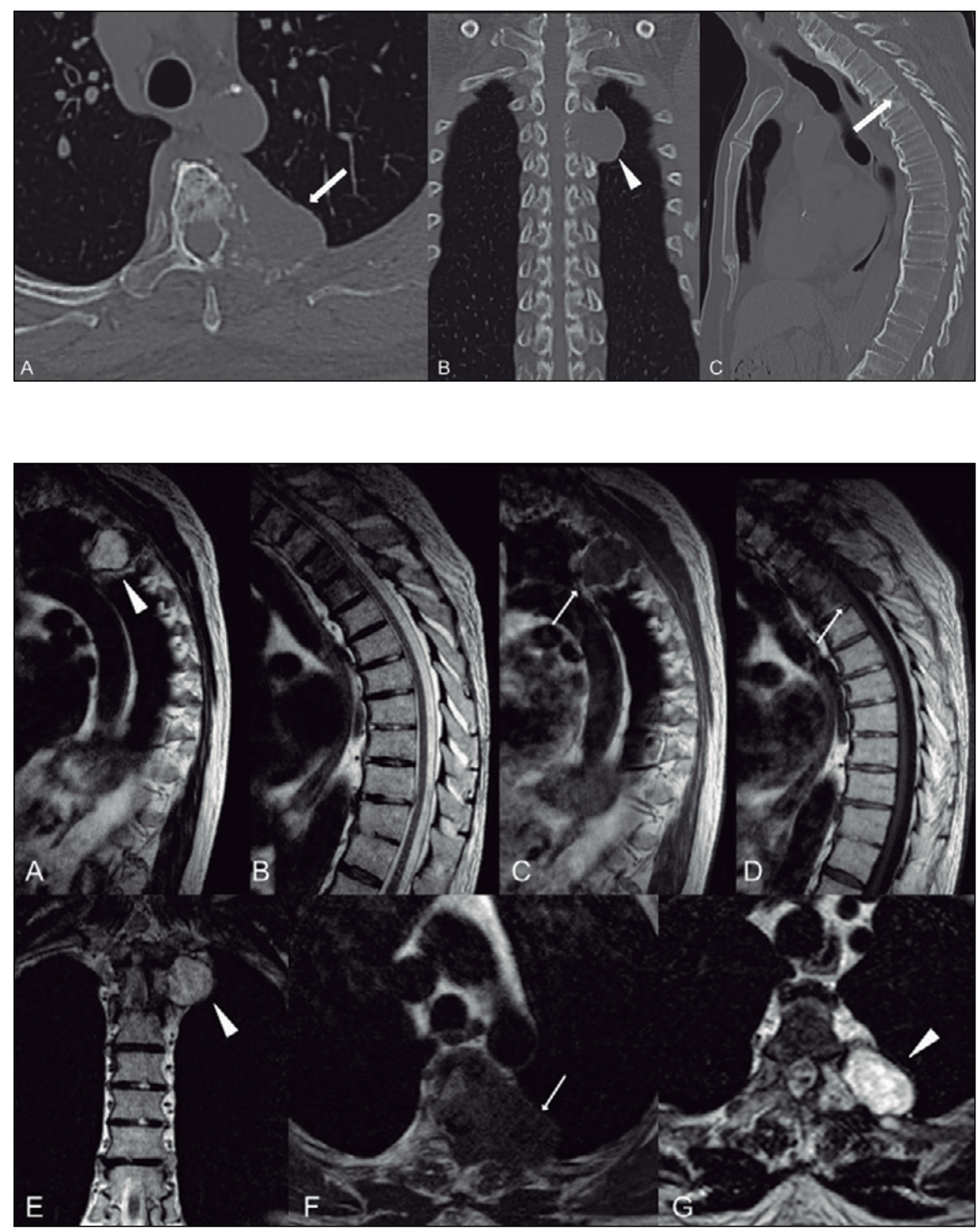

Figura 1. Tomografía Computada preoperatoria. Imágenes axial (A), coronal (B) y sagital (C) de la columna vertebral a nivel de la vértebra T3 en donde se evidencia una lesión lítica que compromete la esquina postero-lateral del cuerpo vertebral, pedículo, apófisis transversa, articulación costo-vertebral y tercera costilla izquierda (flecha). Se evidencia una tumoración paravertebral izquierda que se expande hacia parénquima pulmonar (cabeza de flecha).

Figura 2. Resonancia Magnética sin contraste de columna dorsal preoperatoria. Imágenes parasagitales (A-D), coronal $(\mathbf{E})$ y axiales $(\mathbf{F}$ y $\mathbf{G})$ a nivel de la tercera vértebra dorsal en donde se evidencia una lesión hipointensa en T1 (flecha) e hiperintensa en T2 (cabeza de flecha) que compromete la esquina postero-lateral del cuerpo vertebral, pedículo, apófisis transversa, articulación costo-vertebral y tercera costilla izquierda sin comprometer el canal medular.

geno para Cryptococcus 1/1.000, aunque no se detectaron microorganismos en la tinción con tinta china del LCR. La detección de antígeno en suero también fue positiva en 1/1.000. No se realizó la confirmación del diagnóstico mediante cultivos en sangre y LCR. Para la detección del antígeno se utilizó el método de aglutinación y el kit empleado fue IMMY Latex-Crypto Antigen ${ }^{\circledR}$ como método cuantitativo.

En una primera instancia no se indicó tratamiento quirúrgico. Se inició terapia antifúngica de inducción con anfotericina B liposomal $5 \mathrm{mg} / \mathrm{kg} /$ día durante tres semanas y posteriormente una fase de consolidación con fluconazol $400 \mathrm{mg} /$ día, vía oral. Si bien el protocolo de tratamiento ${ }^{8}$ incluye el uso de flucitosina en la inducción antifúngica durante un período mínimo de dos semanas, en este caso no se indicó debido a que en Argentina no disponemos de este fármaco.

A los cinco meses de iniciado el tratamiento antifúngico el paciente se encontraba con mayor dolor dorsal de características mecánicas. Se solicitaron nuevos estudios por imágenes y se constató la falta de reducción del tamaño de la masa infecciosa. Debido a la imposibilidad 


\section{Caso Clínico}

Figura 3. Cortes histológicos de la muestra tomada del paciente por punción biopsia guiada por tomografía computada. Las imágenes $\mathbf{A}$, C y $\mathbf{E}$ son con un aumento de 40x y las imágenes B, D y F con 400x. En la muestra de tinción de hematoxilina y eosina (A y B) se evidencian numerosas levaduras redondeadas, cápsuladas e intracelulares. Las mismas resultan negativas en hematoxilina y eosina ( $\mathbf{A}$ y B), e intensamente positivas para PAS (Periodic Acid-Schiff) (C y D) y Grocott (E y F).
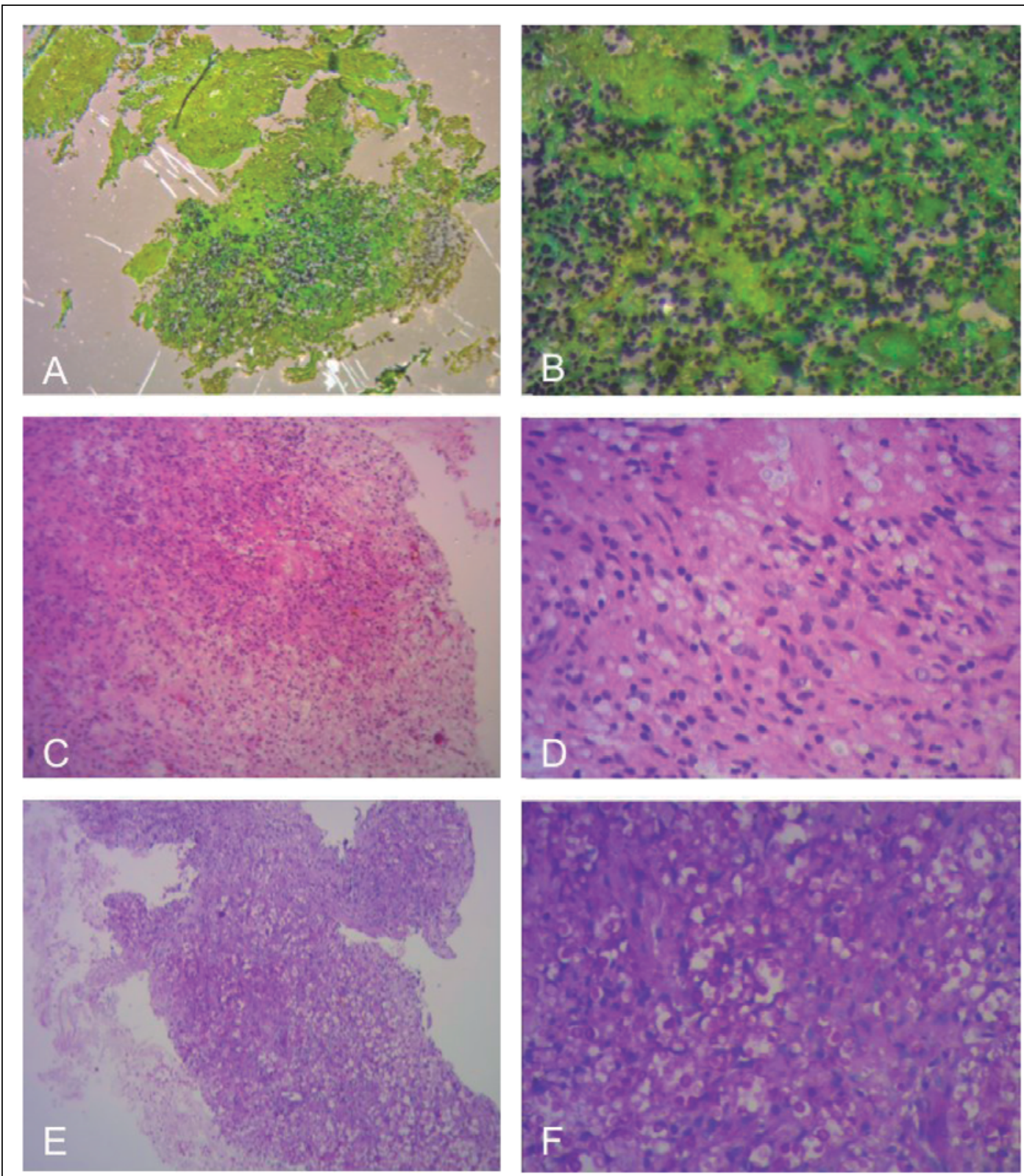

de control infectológico y a la inestabilidad mecánica de su columna, se indicó una cirugía para reducir la masa infecciosa y estabilizar el sector vertebral comprometido por medio de una artrodesis desde T2 a T6.

Se realizó un abordaje posterior dorsal desde T2 a T6 sobre línea media y se instrumentó con tornillos pediculares y barras de titanio en el lado contralateral a la lesión para otorgarle estabilidad. Se identificó a nivel de T3 una tumoración con compromiso de articulación costo-transversa y pedicular izquierda. La lesión fue desbridada y se envió tejido a anatomía patológica y a cultivo (Figura 4). La histología fue similar a la punción biopsia realizada previamente (Figura 3) y el micológico directo de la muestra evidenció múltiples elementos levaduriformes capsulados. Sin embargo, el cultivo micológico fue negativo.

El paciente continuó el tratamiento con fluconazol vía oral a dosis de $400 \mathrm{mg} /$ día. El control infectológico se realizó con parámetros inflamatorios (PCR y VES) y con control de antígeno cuantitativo para Cryptococcus spp. en sangre mediante aglutinación. Éste último se utilizó para determinar la duración del tratamiento 
hasta su negativización que ocurrió a los siete meses post-quirúrgicos (12 meses en total de antifúngicos). El valor inicial al momento del diagnóstico fue de 1/1000, a partir de ese momento se repitió la detección al mes y luego bimensualmente. Los valores fueron de 1/100 para las siguientes mediciones, resultando negativos a los 12 meses del diagnóstico, momento en que se suspendió la terapia antifúngica.

Al año de la cirugía, el paciente se encontraba evolucionando satisfactoriamente, pudiendo realizar sus actividades cotidianas, sin restricciones. No se detectaron complicaciones relacionadas con el procedimiento hasta el último seguimiento.

\section{Revisión bibliográfica}

Realizamos una revisión de la bibliografía disponible sobre los casos publicados de criptococosis vertebral aislada en la base de datos de Medline (PubMed) (Tabla 1).

Se utilizaron los términos MeSH: "cryptococcosis"; "osteomyelitis"; "spine" . Se establecieron como criterios de inclusión: 1) artículos en inglés; 2) publicados desde 1950 en adelante; 3) pacientes con diagnóstico de osteomielitis vertebral por Cryptococcus spp. aislada y 4) sin evidencia de criptococosis pulmonar y/o meníngea.

Según nuestra revisión, detectamos 25 casos de osteomielitis vertebral aislada por Cryptococcus spp. desde $1960^{1,2,5-7}$. Diez de ellas fueron recopiladas en la revisión realizada por Wood y Miedzinski ${ }^{2}$ en 1996, las otras 12 fueron publicadas por Medaris y cols. ${ }^{1}$ en 2016 . Nosotros exponemos, de estas referencias, solo los casos con compromiso de columna vertebral. Posterior a la publicación de Medaris, encontramos tres casos más de osteomielitis vertebral que sumamos a la serie $\mathrm{e}^{5-7}$.

El promedio de edad de los pacientes, incluyendo nuestro caso, fue de 35 años con un rango de 1 a 84 años; 14 pacientes eran de sexo masculino y 12 femenino.

El nivel vertebral afectado con mayor prevalencia fue T3 (cinco casos de 26), seguido en frecuencia por T4, T5 y T8 (cuatro casos cada uno de 26), sin encontrarse una causa específica.

A pesar de que se ha relacionado esta infección con pacientes que presentan alteraciones en la inmunidad celular o con algún grado de inmunocompromiso; nueve de los 26 casos de criptococosis vertebral $(34,5 \%)$ no presentaban estas características. En el resto de los pacientes, cinco tenían diagnóstico de sarcoidosis en tratamiento crónico con corticoesteroides, cuatro presentaban tuberculosis en tratamiento, dos tenían diabetes mellitus insulino-requirientes y el resto presentaban, en igual número, diagnósticos de artritis reumatoidea, infección por VIH, un trauma grave abierto de columna, hepatitis crónica, osteosarcoma, trasplante renal y un caso de cáncer

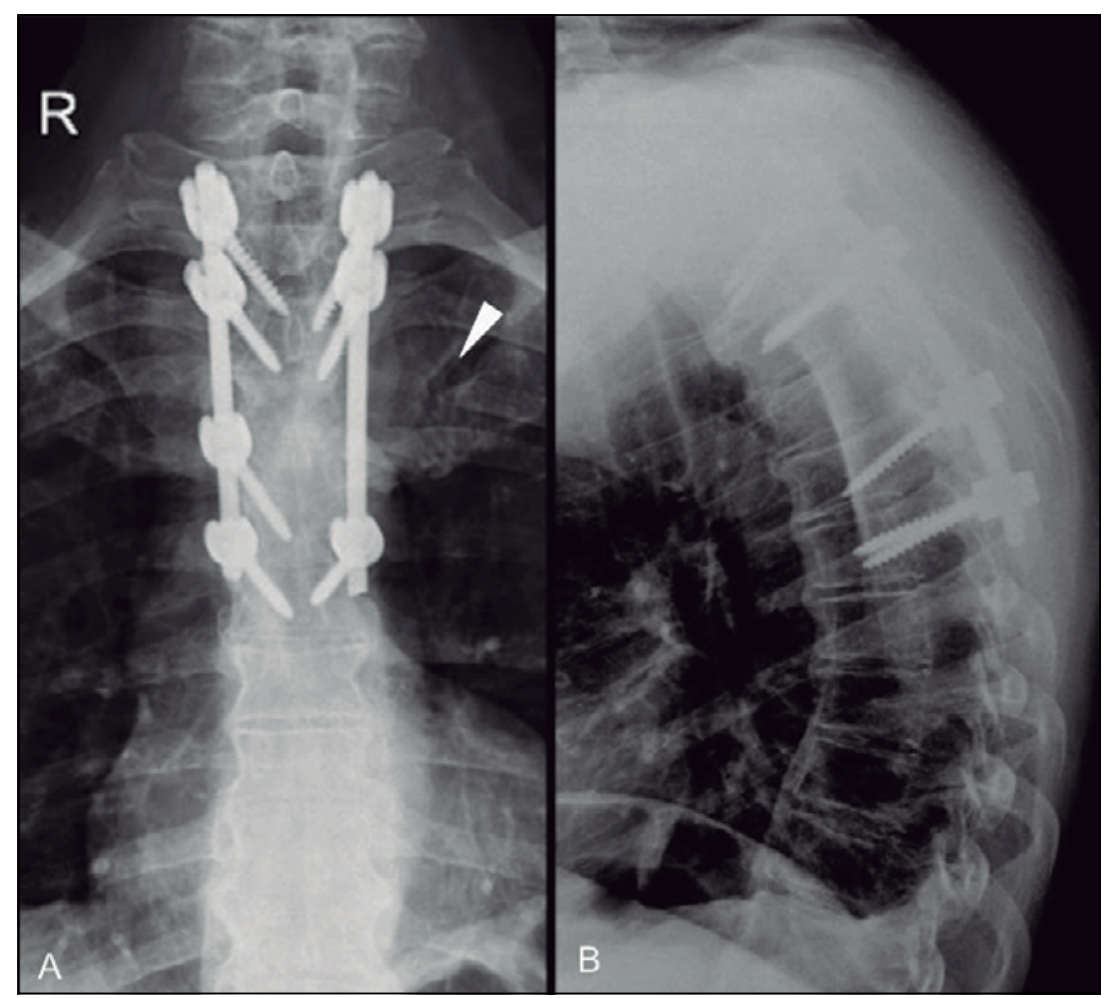

Figura 4. Radiografías de columna dorsal antero-posterior (A) y lateral (B) donde se evidencia la instrumentación con tornillos pediculares desde T2 a T6. Puede observarse la resección parcial del arco posterior de la tercera costilla izquierda (punta de flecha).

pulmonar diagnosticado post-mortem.

Nuestro paciente presentaba como factor de riesgo más importante una inmunosupresión crónica por medicamentos, debido su trasplante renal y diabetes mellitus de 25 años de evolución.

\section{Discusión}

La afectación ósea por Cryptococcus spp. es poco común, con una prevalencia estimada de $5-10 \% \%^{2}$ en el contexto de una infección diseminada. La osteomielitis criptocóccica aislada como la única manifestación de la enfermedad extrapulmonar y fuera del SNC es muy infrecuente y ocurre como resultado de una diseminación hematógena después de una infección pulmonar primaria $^{2,9}$. Otras fuentes potenciales son los traumatismos óseos, embolias sépticas, o la infección de la piel o neural contigua $^{10}$. Wood y Miedzinski, en 1996, publicaron una revisión de todas los casos de infecciones esqueléticas publicadas por C. neoformans, identificando $45 \operatorname{casos}^{2}$, diez de esos casos presentaban una osteomielitis fúngica en la columna vertebral. Del mismo modo Medaris y 


\begin{tabular}{|c|c|c|c|c|c|c|c|c|}
\hline Pte & Autor/Año [ref] & Edad & Sexo & $\begin{array}{c}\text { Sitio } \\
\text { involucrado }\end{array}$ & $\begin{array}{l}\text { Condición médica } \\
\text { asociada }\end{array}$ & Tratamiento antifúngico & $\begin{array}{l}\text { Desbridamiento } \\
\text { quirúrgico }\end{array}$ & Seguimiento \\
\hline 1 & Bernard/1960² & 44 & $\mathrm{~F}$ & T4 & Sarcoidosis & Anfo, SED & NO & 11 meses asintomática \\
\hline 2 & Koshi/1964² & 32 & $\mathrm{~F}$ & $\mathrm{~T} 2, \mathrm{~T} 3$ & Ninguna & Anfo, SED & $\mathrm{SI}$ & Paraparesia a los 4 meses \\
\hline 3 & Morris/1965² & 17 & M & $\mathrm{L} 1,12^{\mathrm{a}}$ costilla & $\begin{array}{l}\text { Traumatismo abierto } \\
\text { lumbar previo }\end{array}$ & Anfo, SED & $\mathrm{SI}$ & 27 meses asintomático \\
\hline 4 & $\begin{array}{l}\text { Balasubrama- } \\
\text { niam } / 1973^{2}\end{array}$ & 34 & $\mathrm{~F}$ & T5, 5ta costilla & Sarcoidosis & ND & ND & $\begin{array}{l}\text { Óbito durante biopsia qui- } \\
\text { rúrgica por supuesto TEP }\end{array}$ \\
\hline 5 & Bryan $/ 1977^{2}$ & 26 & M & T5, T6, T7, T8 & Ninguna & Anfo $\times 10$ sem & NO & 1 año asintomático \\
\hline 6 & Poliner/1979² & 1 & M & $\mathrm{C} 2, \mathrm{C} 3$ & Ninguna & Anfo + 5-FC, SED & $\mathrm{SI}$ & 16 meses asintomático \\
\hline 7 & Matsushita/1985² & 50 & M & T9, T10, T11 & Hepatitis crónica & Anfo + 5-FC, SED & $\mathrm{SI}$ & 2 años asintomático \\
\hline 8 & Lie/1989² & 27 & $\mathrm{~F}$ & L2, L3 & Ninguno & $\begin{array}{c}\text { Anfo } \times 7 \text { sem, } \\
\text { luego } 5-F C \times 7 \text { sem }\end{array}$ & NO & $\begin{array}{l}\text { Mejoria radiográfica a las } \\
7 \mathrm{sem}\end{array}$ \\
\hline 9 & Kromminga/1990² & 84 & M & $\mathrm{T} 10, \mathrm{~T} 11$ & $\begin{array}{l}\text { CA pulmón (Dx en } \\
\text { autopsia) }\end{array}$ & Ninguno & NO & Dx en autopsia \\
\hline 10 & Cure/19912 & 42 & M & T8, T9, T10 & Sarcoidosis & Anfo, SED & ND & ND \\
\hline 11 & Govender/19991 & 6 & $\mathrm{~F}$ & $\mathrm{~T} 4, \mathrm{~T} 5$ & Tuberculosis & Anfo, SED & $\mathrm{SI}$ & $\begin{array}{l}\text { Obito por meningitis pos- } \\
\text { terior }\end{array}$ \\
\hline 12 & Govender/19991 & 43 & $\mathrm{~F}$ & L3 & Diabetes mellitus & Anfo, SED & SI & Asintomática \\
\hline 13 & Govender/19991 & 31 & M & $\mathrm{T} 4, \mathrm{~T} 5$ & Ninguna & Anfo, SED & SI & $\begin{array}{l}\text { Disfunción motora severa } \\
\text { residual }\end{array}$ \\
\hline 14 & Govender/19991 & 27 & M & T8, T9 & Tuberculosis & Anfo, SED & SI & Asintomático \\
\hline 15 & Govender/19991 & 38 & M & $\mathrm{T} 11, \mathrm{~T} 12$ & Ninguna & Anfo, SED & $\mathrm{SI}$ & Asintomático \\
\hline 16 & Govender/19991 & 35 & M & T8 & VIH & Keto $\times 4$ sem & $\mathrm{SI}$ & Asintomático \\
\hline 17 & Govender/19991 & 23 & $\mathrm{~F}$ & $C 4, C 5$ & Ninguna & Keto $\times 4$ sem & SI & Asintomática \\
\hline 18 & Govender/19991 & 25 & $\mathrm{~F}$ & $\mathrm{~T} 1, \mathrm{~T} 2, \mathrm{~T} 3$ & Sarcoidosis & $\begin{array}{l}\text { Fluco x } 2 \text { semanas, luego Anfo } \\
+ \text { Fluco, luego Fluco }+5-F C \times \\
12 \text { meses }\end{array}$ & NO & 2 años. Asintomática \\
\hline 19 & Gupta/2003' & 24 & $\mathrm{~F}$ & T3 y 3ra costilla & Tuberculosis & Anfo +5 FC SED & $\mathrm{SI}$ & Óbito a las 2 sem POP \\
\hline 20 & Wildstein/2005' & 20 & M & $\mathrm{T} 12, \mathrm{~L} 1, \mathrm{~L} 2$ & Sarcoidosis & Fluco SED & NO & 6 meses. Asintomático \\
\hline 21 & Al-Tawfiq/2007 & 34 & $\mathrm{~F}$ & Vértebra Lumbar & Tuberculosis & Fluco $\times 3$ meses & NO & 1 año. Asintomática \\
\hline 22 & Zhou/20131 & 40 & $\mathrm{~F}$ & $\llcorner 4$ & $\begin{array}{l}\text { Artritis reumatoidea } \\
\text { y esclerodermia }\end{array}$ & Fluco $\times 6$ meses & NO & 12 meses. Asintomática \\
\hline 23 & Wang/2014 & 67 & M & $\mathrm{T} 2, \mathrm{~T} 3$ & Ninguna & $\begin{array}{l}\text { Voriconazol } 8 \mathrm{sem} \text {, } \\
\text { luego Fluco } \times 4 \text { sem }\end{array}$ & $\mathrm{SI}$ & ND \\
\hline 24 & Hyun/2015 & 66 & $\mathrm{~F}$ & L2 & Ninguna & $\begin{array}{l}\text { Anfo + Fluco iv } 1 \text { sem, } \\
\text { luego Fluco iv } 1 \text { año }\end{array}$ & SI & 1 año. Asintomática \\
\hline 25 & Qi/20175 & 25 & M & L1 y S1 & Osteosarcoma & $\begin{array}{l}\text { Anfo iv } 4 \text { sem, } \\
\text { luego Fluco vo } 8 \text { sem }\end{array}$ & SI & 9 meses. Asintomático \\
\hline 26 & Pereira Duarte & 65 & M & $\mathrm{T} 3, \mathrm{~T} 4$ & $\begin{array}{l}\text { Diabetes mellitus + } \\
\text { trasplante renal }\end{array}$ & $\begin{array}{l}\text { Anfo iv } \times 3 \text { sem, } \\
\text { luego Fluco vo } 1 \text { año }\end{array}$ & SI & 1 año. Asintomático \\
\hline
\end{tabular}


cols. ${ }^{1}$ realizaron una revisión de 39 casos de osteomielitis criptocóccica aislada, de los cuales 12 presentaban compromiso espinal.

La mayoría de los casos fueron por la especie $C$. neoformans, la cual presenta una distribución universal. Cryptococcus gattii se encuentra restringido a ciertas áreas geográficas y existe escasa información en la literatura médica sobre infecciones óseas por esta especie. Este organismo ha sido identificado en el medio ambiente en árboles de Eucalyptus y es endémico en Australia y otras regiones tropicales ${ }^{11}$.

Los pacientes con osteomielitis criptocóccica generalmente se presentan con semanas o meses de evolución de dolor localizado y tumefacción en la región afectada ${ }^{2}$. A menudo faltan signos sistémicos de enfermedad, como fiebre, sudoración y pérdida de peso, lo cual podría explicarse por el inmunocompromiso y la falta de respuesta inflamatoria.

Las radiografías generalmente muestran lesiones óseas líticas, a menudo con una mínima reacción perióstica sin esclerosis circundante y, a veces, una masa de tejidos blandos adyacente, hallazgos que pueden simular infecciones por micobacterias o neoplasias primarias del hueso ${ }^{6}$.

Los diagnósticos diferenciales incluyen otras infecciones micóticas, así como infecciones bacterianas por Staphylococcus aureus ${ }^{12}$ y bacterias menos comunes como Brucella spp ${ }^{13}$, Actinomyces spp, M. tuberculosis ${ }^{14}$ y micobacterias atípicas. Entre las lesiones neoplásicas se encuentran el mieloma múltiple, metástasis y otros sarcomas óseos ${ }^{6}$.

Aunque infrecuente, la infección por Cryptococcus spp. en pacientes sometidos a trasplante renal está descrita, pero se desconoce su incidencia. En Argentina, la incidencia de criptococosis meníngea en pacientes con VIH, es de 6 a $15 \%{ }^{15}$, por lo que deducimos que el compromiso óseo en personas sin VIH es mucho menor. Debido a esto se requirió de los resultados de los análisis histopatológicos y micológico directo de la muestra quirúrgica para tener el diagnóstico de certeza en nuestro caso.

El tratamiento óptimo para la enfermedad criptocóccica extrapulmonar no se encuentra bien definido. Las recomendaciones internacionales para la enfermedad criptocócica no meníngea, se basan en series retrospectivas $y$ en la opinión de expertos ${ }^{16-18}$. La mayoría coincide en que el fluconazol es suficiente para el tratamiento de los pacientes con criptococosis ósea localizada. Algunos han sugerido que la criptococosis ósea se trate inicialmente con formulaciones lipídicas de anfotericina B más flucitosina, y una vez obtenida la mejoría clínica continuar con fluconazol vía oral si no hay signos de enfermedad diseminada o del $\mathrm{SNC}^{2}$.
Se considera que todos los pacientes con criptococosis esquelética justifican un tratamiento sistémico agresivo intravenoso debido a que la mayoría resultan de la diseminación hematógena desde los pulmones. El papel de la cirugía es disminuir la carga infecciosa, prevenir la afectación leptomeníngea y controlar la estabilidad mecánica $^{10,19}$.

En nuestra revisión, los esquemas de tratamiento antifúngico variaron entre uno a 12 meses. La mayoría de los pacientes recibieron tratamiento combinado, quirúrgico más terapia antifúngica (16 de 26 pacientes). En dos casos no se hizo referencia al tratamiento quirúrgico (casos 4 y 10 de nuestra serie). Las indicaciones de cirugía fueron por una colección o masa fúngica que no respondía al tratamiento médico, síntomas mecánicos por compromiso de la estabilidad vertebral o por compromiso neurológico. En nuestro paciente se decidió inicialmente el tratamiento conservador de la lesión. Se inició tratamiento antifúngico con anfotericina $\mathrm{B}$ durante tres semanas y posteriormente fluconazol vía oral. Sin embargo, a los cinco meses de tratamiento los síntomas de inestabilidad mecánica vertebral empeoraron, por lo que se indicó la intervención quirúrgica.

A pesar de que los resultados clínicos de nuestra revisión son variados, la mayoría de los informes (14 de 26 casos) reportan pacientes asintomáticos luego de 12 meses de tratamiento antifúngico.

Nuestro paciente se encuentra asintomático al año de seguimiento con antígeno criptocóccico no cuantificable en suero luego de 12 meses de tratamiento antifúngico.

\section{Resumen}

La criptococosis es una micosis sistémica producida por un hongo levaduriforme encapsulado denominado Cryptococcus neoformans. Es una enfermedad universal, que ocurre con mayor frecuencia en pacientes inmunocomprometidos, manifestándose principalmente como una enfermedad diseminada con compromiso meníngeo o pulmonar. Sin embargo, la osteomielitis ocurre solo en $5-10 \%$ de los casos, siendo el compromiso vertebral el más frecuente. Presentamos un caso de criptococosis vertebral aislada y una búsqueda bibliográfica sobre el tema. Se recomienda realizar una terapia antifúngica de inducción intravenosa y continuar con una fase de consolidación, vía oral, de duración variable. La indicación quirúrgica se considera en lesiones que comprometen la estabilidad vertebral y aquellas que presentan un compromiso neurológico, producen deformidad y para reducir el inóculo infeccioso. 


\section{Referencias bibliográficas}

1.- Medaris L A, Ponce B, Hyde Z, Delgado D, Ennis D, Lapidus W, et al. Cryptococcal osteomyelitis: a report of 5 cases and a review of the recent literature. Mycoses 2016; 59: 33442. doi: $10.1111 /$ myc. 12476 .

2.- Wood L, Miedzinski L. Skeletal cryptococcosis: case report and review of the literature. Can J Infect Dis 1996; 7: 125-32.

3.- Nottebart H C, McGehee R F, Utz J P L. Cryptococcus neoformans osteomyelitis: case report of two patients. Sabouraudia 1974; 12: 127-32.

4.- Collins V P. Bone involvement in cryptococcus (torulosis). Am J Roentgenol 1950; 63: 102-12.

5.- Qi L, Yuan L, Xionglong Y, Xin L, Qiang W, Yibiao Z, et al. Diagnosis and treatment of nonadjacent cryptococcal infections at the L1 and S1 vertebrae. Orthopäde 2017; 46: 85-89. doi: 10.1007/s00132-016-3349-3.

6.- Joo H S, Ha J K, Hwang C J, Lee D H, Lee C S, Cho J H. Lumbar cryptococcal osteomyelitis mimicking metastatic tumor. Asian Spine J 2015; 9: 798-802. doi: 10.4184/ asj.2015.9.5.798.

7.- Wang C, Jia N, Zhang L, Liu K, Liu H, Yu H. Imaging finding of cryptococcal infection of the thoracic spine. Int J Infect Dis 2014; 29: 162-5. doi: 10.1016/j.ijid.2014.07.013.

8.- Perfect J R, Dismukes W E, Dromer F,
Goldman D L, Graybill J R, Hamill R J, et al. Clinical practice guidelines for the management of cryptococcal disease: 2010 update by the Infectious Diseases Society of America. Clin Infect Dis 2010; 50: 291-322. doi: 10.1086/649858

9.- Zhou H X, Lu L, Chu T, Wang T, Cao D, Li F, et al. Skeletal cryptococcosis from 1977 to 2013. Front Microbiol 2015; 5: 740. doi: 10.3389/fmicb.2014.00740.

10.- Armonda R A, Fleckenstein J M, Brandvold B, Ondra S L. Cryptococcal skull infection: a case report with review of the literature. Neurosurgery 1993; 32: 1034-6.

11.- Speed B, Dunt D. Clinical and host differences between infections with the two varieties of Cryptococcus neoformans. Clin Infect Dis 1995; 21: 28-34.

12.- Petracchi M, Campaner G, Gruenberg M, Valacco M, Solá C. Espondilodiscitis cervical hematógena. Diagnóstico y tratamiento. Serie consecutiva de once pacientes. Rev Asoc Argent Ortop Traumatol 2008; 3: 268-76.

13.- Campaner G, Solá C, Monayer J L, Gruenberg M. Espondilitis cervical brucelósica. Comunicación de un caso y revisión bibliográfica. Rev Asoc Argent Ortop Traumatol 2006; 4: 341-4.

14.- Petracchi M, Camino Willhuber G, Tripodi M L, Bassani J, Gruenberg M, Sola C. Monosegmental combined anterior posterior instrumentation for the treatment of a severe lumbar tuberculous spondylodiscitis: case report and literature review. Rev Bras Ortop 2017; 52: 735-9.

15.- Luque Aguada L, Fraenza L, Raga A J. Criptococosis e histoplasmosis diagnosticadas en pacientes con VIH/SIDA en un período de 15 años. http://cobico.com.ar/wp-content/ archivos/2017/09/CRIPTOCOCOSIS-EHISTOPLASM-DIAGN-EN-PTES-CON-VIH. pdf.

16.- Singh N, Husain S, De Vera M, Gayowski T, Cacciarelli T V. Cryptococcus neoformans infection in patients with cirrhosis, including liver transplant candidates. Medicine (Baltimore) 2004; 83:188-92.

17.- Singh N, Lortholary O, Alexander B D, Gupta K L, John G T, Purcell K J, et al. Antifungal management practices and evolution of infection in organ transplant recipients with Cryptococcus neoformans infection. Transplantation 2005; 80: 1033-9.

18.- Singh N, Gayowski T, Marino I R. Successful treatment of disseminated cryptococcosis in a liver transplant recipient with fluconazole and flucytosine, an all oral regimen. Transpl Int 1998; 11:63-5.

19.- Fialk M A, Marcove R C, Armstrong D. Cryptococcal bone disease: a manifestation of disseminated cryptococcosis. Clin Orthop Relat Res 1981;158: 219-23. 